Document downloaded from:

http://hdl.handle.net/10251/71219

This paper must be cited as:

García Cirujano, F.; Corma Canós, A.; Llabrés I Xamena, FX. (2015). Conversion of Levulinic acid into chemicals: Synthesis of biomass derived levulinate esters over $\mathrm{Zr}$ containing MOFs. Chemical Engineering Science. 124:52-60.

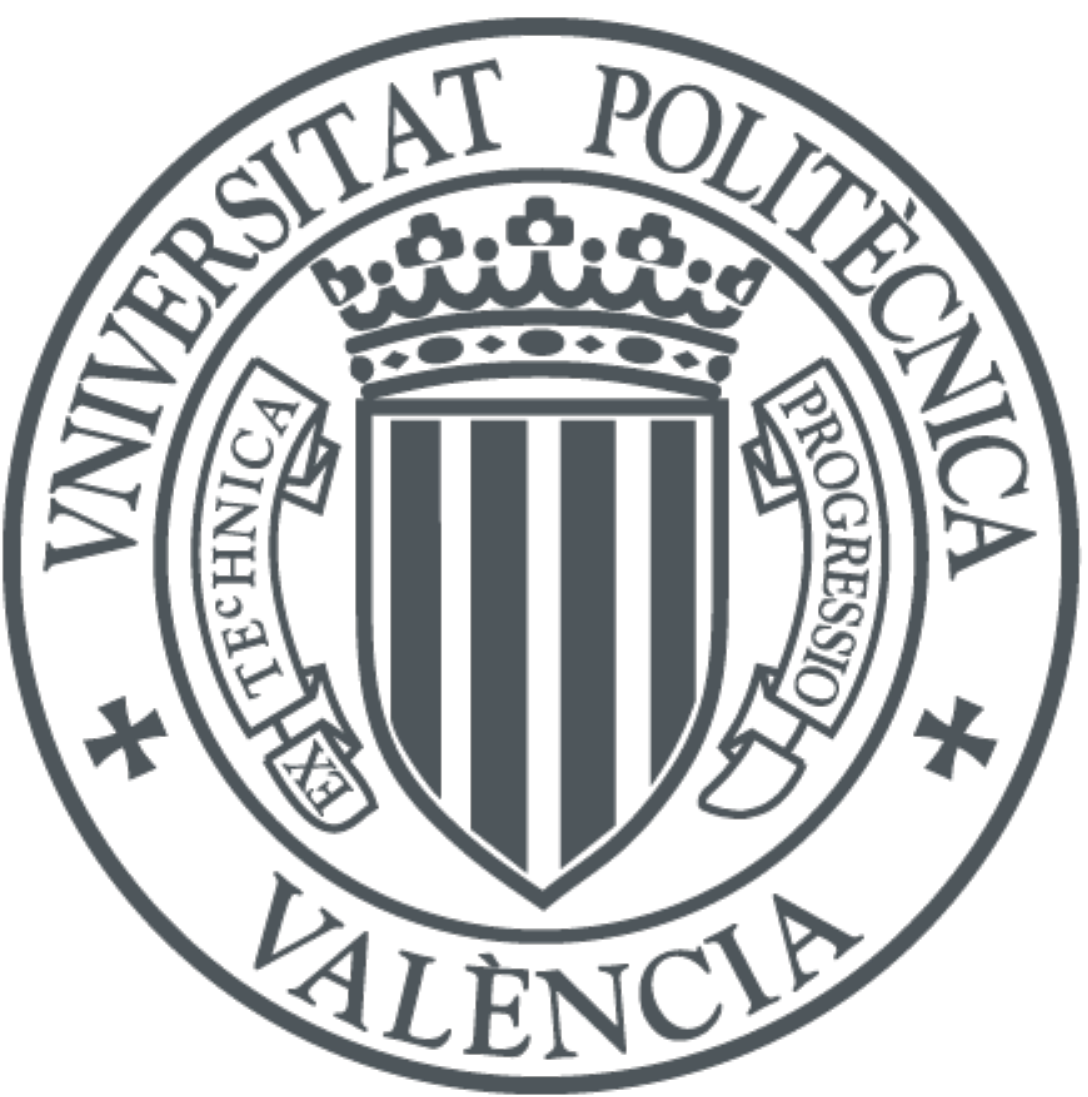

The final publication is available at

http://dx.doi.org/10.1016/j.ces.2014.09.047

Copyright Elsevier

Additional Information 


\title{
Conversion of Levulinic acid into chemicals: Synthesis of biomass derived levulinate esters over $\mathrm{Zr}$-containing MOFs
}

\author{
F. G. Cirujano, A. Corma*, and F. X. Llabrés i Xamena* \\ Instituto de Tecnología Química, Universidad Politécnica de Valencia, Consejo Superior de \\ Investigaciones Científicas, Avda. de los Naranjos, s/n, 46022 Valencia, Spain
}

*Corresponding authors: acorma@itq.upv.es, fllabres@itq.upv.es

\begin{abstract}
Zr-containing metal-organic frameworks (MOFs) formed by terephthalate (UiO-66) and 2-aminoterephthalate ligands $\left(\mathrm{UiO}-66-\mathrm{NH}_{2}\right)$ are active and stable catalysts for the acid catalyzed esterification of levulinic acid with $\mathrm{EtOH}, n-\mathrm{BuOH}$ and long-chain biomass derived alcohols, with activities comparable (in some cases superior) to other solid acid catalysts previously reported. The effect of functional group substitution at the ligand benzene ring, alcohol chain length, particle size and contents of defects on the catalytic activity of the MOFs are studied in detail. In UiO-66- $\mathrm{NH}_{2}$, a dual acid-base activation mechanism is proposed, in which levulinic acid is activated on $\mathrm{Zr}$ sites and the alcohol at the amino groups of the ligand. Large variations of the catalytic activity from batch to batch suggest that the active sites are located at defect positions associated to ligand deficiency of the solid. Particle size seems to have a minor impact only in UiO-66- $\mathrm{NH}_{2}$, in which diffusion of levulinic acid is somehow hindered due to the amino groups present in the linkers.

Keywords: MOF catalysis; biomass into chemicals; levulinic acid esterification; dual acid-base activation.
\end{abstract}




\section{Introduction}

Levulinic acid (LA) is a largely available renewable compound that can be obtained from the deconstruction of lignocellulosic biomass (Corma et al., 2007), and can be used for preparing many other important products in the food and chemical industries. Among them, alkyl levulinate and $\gamma$-valerolactone are important levulinic acid derivatives (Zhang et al., 2012). For instance, the low toxicity, high lubricity, flash point stability and moderate flow properties under low temperature conditions make levulinate esters suitable additives for gasoline and diesel fuels (Hayes, 2009). Thus, ethyl levulinate (EL) is used as an oxygenated diesel additive, with up to $20 \%$ content in the diesel formulation. EL is also a suitable gasoline blendstock due to its high octane rating, good energy content, high lubricity and flashpoint, and its good solubility and volatility compatible with most gasoline blends. Furthermore, the properties of LA esters are similar to biodiesel fatty acid methyl esters (FAME), but they do not have their principal drawbacks of cold flow properties and gum formation (Hayes, 2009). Besides fuel additives, other applications of levulinate esters include their use as flavoring compounds and fragrances, solvents and plasticizers, among others (Corma et al., 2007; Zhang et al., 2012). In the case of levulinate esters, esterification of LA with alcohols is usually carried out under acidic conditions using mineral acids, being concentrated $\mathrm{H}_{2} \mathrm{SO}_{4}$ and $p$-toluenesulfonic acid the most commonly used (Bart et al., 1994). However, the use of mineral acids has some drawbacks such as catalyst recycling, product separation and environmental problems, among others. Therefore, the tendency nowadays is to replace them by solid acid catalysts, which avoid handling corrosion and environmental problems associated with the use of these mineral acids. In this way, heteropolyacids or sulfated metal oxides have been commonly used in the last years.

In recent years, Metal-Organic Frameworks (MOFs) have attracted much interest due to their potential as heterogeneous catalysts (Corma et al., 2010a; Farrusseng et al., 2009; 
Garcia-Garcia et al., 2014; Gascon et al., 2014; Lee et al., 2009; Llabrés i Xamena and Gascon, 2013). MOFs are crystalline porous solids formed by the linkage of metal ions or metal-oxo clusters and polydentate organic linkers, forming three dimensional networks defining regular nanometric pore channels and cavities similar to those found in zeolites. The large number of available metals and organic molecules that can be used to prepare a MOF leads to a virtually infinite number of combinations. This high variability, along with the possibility to introduce new functionalities in a pre-formed MOF by post-synthesis modification (Wang and Cohen, 2009; Zhang et al., 2009), allow to finely tune the chemical compositions, chemical environment and pore structures of the materials and thus, their reactivity. The Lewis acid catalytic properties of MOFs have already been demonstrated for many reactions, including cyanosilylation of carbonyl compounds (Fujita et al., 1994; Henschel et al., 2008; Horike et al., 2008; Schlichte et al., 2004), epoxide methanolysis (Wee et al., 2012), isomerizations of $\alpha$-pinene oxide and citronellal (Alaerts et al., 2006; Cirujano et al., 2012), Friedländer condensation (Pérez-Mayoral and Cejka, 2011), alkene cyclopropanation (Corma et al., 2010b), etc. In many cases, the Lewis acid character of the MOF comes from the creation of a coordination vacancy upon thermal removal of a solvent molecule (usually $\mathrm{H}_{2} \mathrm{O}$ ) initially bound to the metallic nodes. However, in spite of lacking coordination vacancies in their ideal crystalline structure, Zr-containing UiO-66 type MOFs (Cavka et al., 2008) also display the typical reactivity expected for a Lewis acid catalyst (Cirujano et al., 2014; Vermoortele et al., 2011; Vermoortele et al., 2012). According to recent characterization studies (Valenzano et al., 2011), the catalytic activity of these Zr-MOFs would arise from the occurrence of a (thermal) dehydroxylation of the $\left[\mathrm{Zr}_{6} \mathrm{O}_{4}(\mathrm{OH})_{4}\right]^{12+}$ clusters to $\left[\mathrm{Zr}_{6} \mathrm{O}_{6}\right]^{12+}$ exposing $\mu_{3}$-vacancies, together with the systematic formation of crystalline defects associated to linker deficiencies. The crystalline structure of UiO-66 is shown in Figure 1, together with the type of $\mathrm{Zr}^{4+}$ coordination vacancies that are created 
when a linker molecule is missing. Nevertheless, given the well known Lewis acid character of UiO-66 type materials and their noticeable thermal, chemical and mechanical stability (Cavka et al., 2008), we have anticipated that these materials could be good candidates for the conversion of LA.

$<$ Insert Figure 1 near here $>$

Herein we will demonstrate that $\mathrm{Zr}$-containing $\mathrm{UiO}-66$ and $\mathrm{UiO}-66-\mathrm{NH}_{2}$ materials are indeed efficient, stable and reusable catalysts for LA esterification using various alcohols, including the most industrially relevant ethanol and $n$-butanol. Moreover, esterification of LA with long chain alcohols over UiO-type MOFs can also be carried out efficiently, affording a series of biomass-derived compounds with interesting plasticizing properties.

\section{Materials and Methods}

\subsection{Synthesis of the MOFs.}

Four different batches of UiO-66- $\mathrm{NH}_{2}$ (batches A1 to A4) and UiO-66 (batches $\mathrm{B} 1$ to B4) were prepared according to the reported procedure (Kandiah et al., 2010). Briefly, 750mg of $\mathrm{ZrCl}_{4}$ and either $740 \mathrm{mg}$ of terephthalic acid (UiO-66) or $800 \mathrm{mg}$ of aminoterephthalic acid (UiO-66- $\mathrm{NH}_{2}$ ) were dissolved in $90 \mathrm{~mL}$ of DMF (Zr:ligand:DMF molar ratio of 1:1:220) and the solution was keep in a closed round bottom flask at $80^{\circ} \mathrm{C}$ for $12 \mathrm{~h}$ without stirring, followed by another $24 \mathrm{~h}$ at $100^{\circ} \mathrm{C}$ in an oil heating bath. The resulting materials were recovered by filtration and washed thoroughly with fresh DMF. Then the solids were washed three times by soaking them in dichloromethane for three hours. Finally, the solid was recovered by filtration and dried under vacuum. X-ray diffraction (Phillips X'Pert, $\mathrm{Cu}$ $\mathrm{K} \alpha$ radiation) was used to confirm the expected structure type and high crystallinity of the materials. An additional UiO-66- $\mathrm{NO}_{2}$ sample was prepared by simply replacing terephthalic acid by nitroterephthalic acid $(940 \mathrm{mg})$ and maintaining all the procedure the same. 
Further characterization of the MOFs included thermogravimetric analysis, TGA, (Mettler Toledo TGA/SDTA851e) and transmission electron microscopy, TEM (JEOL JEM-1010, operated at $100 \mathrm{kV}$ ) to determine linker deficiencies and average particle size and size distributions of each sample, respectively. Detailed data obtained and procedure used is given as Supporting Information.

\subsection{General procedure for esterification reactions.}

Esterification reactions were performed as follows: $1 \mathrm{mmol}$ of levulinic acid, and the desired amount of alcohol were contacted with the MOF $(0.018 \mathrm{mmol} \mathrm{Zr})$ in a batch reactor at the specified temperature (see footnotes in the corresponding tables for specific conditions). The reaction was followed by GC-MS (Varian 3900) with either a BP20(WAX) column (15 m long, i.d. $0.32 \mathrm{~mm}$ ) for the reaction of LA with ethanol, or a $30 \mathrm{~m}$ long and $0.25 \mathrm{~mm}$ i.d. capillary column HP-5 (5\% phenylmethylpolysiloxane) for the rest of reactions. Dodecane was used as external standard in all cases. Retention times were compared with those of commercial standards when available.

\section{Results and Discussion}

2.1. Production of ethyl levulinate: Esterification of levulinic acid with ethanol over Zr-containing UiO-66-type MOFs

LA was first reacted with ethanol (Scheme 1) in the presence of $\mathrm{Zr}$-containing MOFs UiO-66 and UiO-66- $\mathrm{NH}_{2}$ under the reaction conditions indicated in Table 1.<smiles>CCOC(=O)CCC(C)=O</smiles>

\section{Scheme 1}

Both MOFs were found to be active and selective catalysts for this reaction, converting LA into EL almost quantitatively in about $8 \mathrm{~h}$ (see Figure 1a and Table 1, entries 3 and 5). EL 
was the only product detected in all cases. Under the same reaction conditions, blank experiments in the absence of any MOF catalyst produced $5.4 \%$ yield of the ester after $8 \mathrm{~h}$ (Table 1, entry 1). This activity of the blank arises from the acid character of LA, that can autocatalyze the esterification reaction to some extent. Both materials, i.e., UiO-66 and UiO-66- $\mathrm{NH}_{2}$, showed similar catalytic activities. Moreover, both UiO-66 and UiO-66- $\mathrm{NH}_{2}$ were found to be stable under the reaction conditions (see Fig. S9 in Supporting Information) and the catalysts can be recovered after the reaction and reused for at least 3 cycles without considerable loss of activity (Table 1, entries 4 and 6). Determination of the $\mathrm{Zr}$ content of the used catalysts and of the liquid filtrate after the reaction by ICP-OES demonstrated that the catalytic process was heterogeneous and that the amount of $\mathrm{Zr}$ leached from the solid was only $0.35 \%$ of the total $\mathrm{Zr}$ in the starting MOF.

\section{$<$ Insert Figure 2 near here $>$ \\ $<$ Insert Table 1 near here $>$}

In Table 1 we have also compared the catalytic activity of the UiO-66 type materials with that of $p$-toluene sulfonic acid ( $p$-TSA, Table 1, entry 2). This organic Brønsted acid afforded a TOF of $120 \mathrm{~h}^{-1}$, which is significantly higher than the TOFs of 31 and $29 \mathrm{~h}^{-1}$ calculated for UiO-66 and UiO-66- $\mathrm{NH}_{2}$ when the total $\mathrm{Zr}$ content of the samples was considered.

A fair appraisal of the performance of UiO-types materials for LA esterification with respect to other heterogeneous catalysts described in the literature is only possible when the reaction is performed under the same (or very similar) experimental conditions. Thus, in order to put our results in perspective and to establish meaningful comparisons, we have performed additional experiments with UiO-66 and changing the temperature and the EtOH:LA molar ratio to reproduce experimental conditions used in precedent works. The results obtained are shown in Table 1 (entries 7 and 8). Thus, when the excess of ethanol used for the esterification was reduced three times, from $15: 1$ to $5: 1$, the reaction was considerable 
slower: 78 vs $49 \%$ EL yield obtained after 4 h respectively (compare entries 5 and 7 in Table 1). Nevertheless, the slowdown of the reaction can be largely compensated by increasing the temperature from $78^{\circ} \mathrm{C}$ to $100^{\circ} \mathrm{C}$ (Table 1 , entry 8 ). The results obtained with this lower excess of EtOH can be compared with the values reported by Fernandes et al. for the same reaction using various acid catalysts (Table 1, entries 9-13) (Fernandes et al., 2012). Although not enough information is provided in the original paper to allow us to calculate the TOFs attained with these catalysts, under these conditions the EL yield attained with the MOF is comparable with that of the resin Amberlyst-15 after a similar reaction time (i.e., 55\% EL yield after $5 \mathrm{~h}$ ), and clearly surpasses the EL yields obtained with the other catalysts tested by those authors (between 4\% and 40\%). However, better results have been reported by Li et al. for sulfated mixed $\mathrm{Zr}$ and $\mathrm{Ti}$ oxides and sulfated titania nanorods at $105^{\circ} \mathrm{C}$ (compare entry 8 with entries 14 and 15 in Table 1), using even lower alcohol excess and shorter reaction times (Li et al., 2012), though again not enough information is provided to calculate TOFs. Nandiwale et al. have used Dawson-type heteropolyacid supported on desilylated H-ZSM-5 (DTPA/DHZSM-5) as catalyst for LA esterification (Table 1, entry 16) (Nandiwale et al., 2013). Also in this case the activity of UiO-66 is lower than their best performing catalyst containing supported heteropolyacid, while pristine and desilylated H-ZSM-5 supports were considerably less performing than the MOF (16 and 28\% yield after $4 \mathrm{~h}$, respectively). The same authors studied various pristine and desilylated protonic zeolites (Table 1, entries 17-19), but the results obtained were worse than with the UiO MOFs. Yan et al. have studied the catalytic activity of another heteropolyacid supported on silica for LA esterification using a higher EtOH:LA ratio of 18:1, but the measured activity was lower than that of the Zr-MOFs (compare entry 20 with entries 3-6 in Table 1) (Yan et al., 2013). As expected, the activity of the silica support was negligible under these conditions ( $2 \%$ yield after $6 \mathrm{~h}$ ). Finally, Pasquale et al. have used Wells-Dawson heteropolyacid supported on silica (40WD-S, 
entry 21 in Table 1) as catalyst with a still higher EtOH:LA of 64:1, obtaining 76\% yield of EL after $10 \mathrm{~h}$ (Pasquale et al., 2012).

The above data taken from literature are only some examples that allow us to determine that the catalytic activity of the Zr-MOFs is, except in some case like when acidic sulfated mixed $\mathrm{Zr}$ and Ti oxides were used, very similar or even better than other solid catalysts.

\subsection{Catalytic activity, concentration of defects and particle size of the Zr MOFs}

When checking the reproducibility of the catalytic results obtained with the Zr MOFs, we found that the data were perfectly reproducible (within the experimental errors) as long as the same batch sample was used. However, a large variation of the catalytic properties existed from batch to batch sample, even when materials prepared (in principle) with the same synthesis procedure were always used. These variations were more pronounced in UiO-66 than in UiO-66- $\mathrm{NH}_{2}$ samples, as evidenced in Figure 2a and b. Thus, in the case of UiO-66, calculated kinetic rate constants (see below) varied between $0.61 \mathrm{~h}^{-1}$ and $0.07 \mathrm{~h}^{-1}$, i.e., an almost 9-fold increase from the less active to the most active material. Therefore, we were prompted to investigate what was the origin of this high variability of catalytic properties.

\section{$<$ Insert Figure 3 near here $>$}

In a previous study, we pointed out that the presence of structural defects and also of phase impurities in the zinc terephthalate IRMOF-3 may have a critical effect on the reaction rate of acid-catalyzed reactions (Llabrés i Xamena et al., 2012). Similarly, the Lewis acid properties of UiO-type materials arise (at least partially) from the formation of crystalline defects associated to linker deficiencies, as already established in previous works by the groups of Lamberti (Valenzano et al., 2011) and De Vos (Vermoortele et al., 2012). Indeed, 
the analysis of the thermogravimetric (TGA) curves of these Zr-MOFs indicates that the amount of organic linker (either terephthalate or aminoterephthalate for UiO-66 and UiO-66- $\mathrm{NH}_{2}$, respectively) with respect to the inorganic residue $\left(\mathrm{ZrO}_{2}\right.$ in both cases) is systematically lower that the expected from the ideal stoichiometry of the MOF, the exact fraction depending on the particular synthesis conditions of the sample. In order to study the possible influence of the linker deficiency on the observed rates of LA esterification, we have determined for each of the batches of Zr-MOFs the linker deficiency of the catalyst and the corresponding rate constant $\left(k, \mathrm{~h}^{-1}\right)$ for the esterification reaction. The kinetic rate constant was obtained from the fitting of the kinetic data shown in Figure 2 to a pseudo-first order kinetic rate equation (see Supporting Information). All the materials were prepared (in principle) with the same two-steps synthetic procedure, as described by Kandiah et al. (Kandiah et al., 2010) (see Experimental Section). However, small differences in the nucleation and crystal growth rates due to stochastic variations in the temperature, time or reagent concentrations in the synthesis from batch to batch were found to be enough to produce a set of materials with very different properties in terms of particle size, linker deficiency and catalytic activity. The detailed procedures used to determine linker deficiency, particle size and rate constants are given in the Supporting Information.

After careful analysis of the different batches of UiO-66 and UiO-66- $\mathrm{NH}_{2}$ prepared, we found that highly crystalline materials were always obtained (Fig. S1 in Supporting Information), with linker deficiencies ranging from 2.5 to $13.2 \%$ for UiO-66, and between 2.1 and $8 \%$ for $\mathrm{UiO}-66-\mathrm{NH}_{2}$, as determined from the corresponding TGA curves following the procedure described by (Valenzano et al., 2011). The linker deficiencies thus calculated correspond to linker-to-cluster ratios comprised between 11.75 (for the less defective UiO-66- $\mathrm{NH}_{2}$ material) and 10.42 (for the most defective UiO-66 material), thus being always below the value of 12 expected for the ideal stoichiometry. 
We have observed a clear dependence of the LA esterification rate constant $(k)$ on the linker deficiency in UiO-66 and UiO-66- $\mathrm{NH}_{2}$, as shown in Figure 2c. Thus, for each material the values of $k$ gradually increase with the linker deficiency following a linear trend. To confirm this tendency, we prepared an additional material, UiO-66- $\mathrm{NO}_{2}$, following the same synthesis procedure as that used for $\mathrm{UiO}-66$ and $\mathrm{UiO}-66-\mathrm{NH}_{2}$. This $\mathrm{UiO}-66-\mathrm{NO}_{2}$ sample was found to contain a very low linker deficiency of only $0.4 \%$, corresponding to a linker-to-cluster ratio of 11.95 , very close to the ideal value of 12 . Accordingly, the measured activity for LA esterification was very low, thus following the general trend found for the other isoreticular materials (symbol * in Figure $2 \mathrm{c}){ }^{1}$

As commented above, if one calculates the turnover frequency (TOF) taking into account the total zirconium content of the catalyst, the values obtained are 31 and $29 \mathrm{~h}^{-1}$ for the most active UiO-66 and UiO-66- $\mathrm{NH}_{2}$ samples, respectively. However, if we consider that only the $\mathrm{Zr}$ ions associated to linker defects are the active sites for the esterification reaction, the TOFs can be recalculated. In the MOF structure, each terephthalate (or aminoterephthalate) linker is connected to $4 \mathrm{Zr}$ ions. However, two of these $\mathrm{Zr}$ ions must be saturated by ${ }^{-} \mathrm{OH}$ or $\mathrm{Cl}^{-}$anions to preserve the electrical neutrality of the material, thus leaving two coordinatively unsaturated sites per missing linker molecule, as shown in Scheme 2. Therefore, recalculated TOF for the most active UiO-66 sample (containing 13.2\% linker deficiencies and twice as much coordinatively unsaturated sites) is $117 \mathrm{~h}^{-1}$, which is very close to the value of $120 \mathrm{~h}^{-1}$ obtained for $p$-TSA (see entry 2 in Table 1 ).

\footnotetext{
1 All our attempts to prepare UiO-66- $\mathrm{NO}_{2}$ samples produced materials with practically the same values of linker deficiency, therefore making it difficult to confirm if the dependency of the reaction rate constant with defect concentration obeys also a linear trend, as in UiO-66 and UiO-66- $\mathrm{NH}_{2}$.
} 


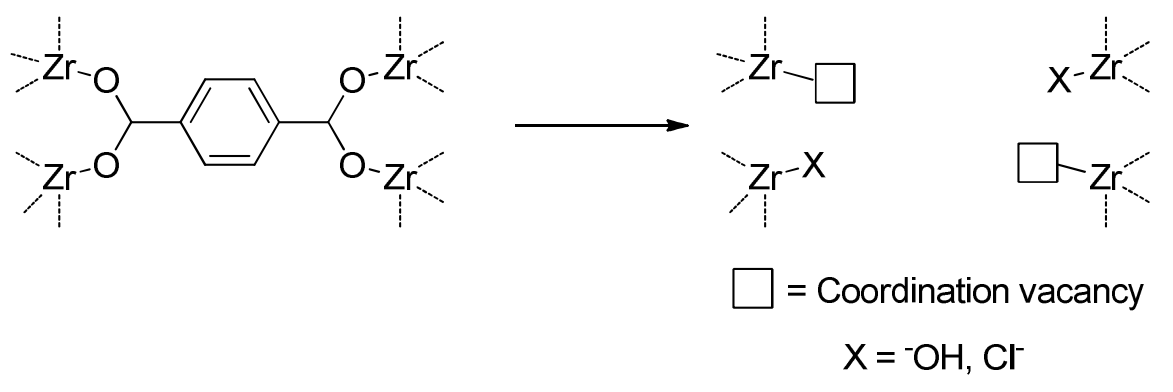

\section{Scheme 2}

For UiO-66- $\mathrm{NH}_{2}$, having $6.3 \%$ of linker defects, the calculated TOF is considerably higher: $230 \mathrm{~h}^{-1}$. Furthermore, according to the data shown in Figure 2c, the UiO-66- $\mathrm{NH}_{2}$ samples are in general slightly more active than the UiO-66 with the same linker deficiencies. This could be due to a cooperative action of the (basic) amino groups that are located adjacent to the (acid) $\mathrm{Zr}$ sites of UiO-66- $\mathrm{NH}_{2}$, thus leading to a bifunctional acid-base catalyst, as already proposed for cross-aldol condensation (Vermoortele et al., 2011), $\mathrm{CO}_{2}$ cycloaddition to styrene oxide (Kim et al., 2013), or fatty acid esterification over UiO-66- $\mathrm{NH}_{2}$ materials (Cirujano et al., 2014). This could lead to a dual activation mechanism, in which levulinic acid would adsorb onto the $\mathrm{Zr}$ acid sites, thus increasing the electrophilic character of the carboxylic carbon atom. Meanwhile, even if the $-\mathrm{NH}_{2}$ groups in UiO-66- $\mathrm{NH}_{2}$ are not basic enough to deprotonate the alochol, they can still form hydrogen bonded adducts, which will increase the nucleophilic character of the $\mathrm{O}$ atom of the alcohol, thus favoring the condensation with the activated carboxylic carbon of the acid. In order to confirm or rule out the occurrence of a dual acid-base activation mechanism operating in $\mathrm{UiO}-66-\mathrm{NH}_{2}$, we designed a set of additional experiments. First, the reaction between LA and EtOH in the presence of various amine bases: aniline and dimethylaminoterephthalate, DMATA, was studied. The objective was to determine whether or not the esterification of LA can be catalyzed by such weak bases. As expected, the amount of ethyl levulinate formed was practically the same (or even lower) than in the blank experiment (i.e., without any catalyst added) (see Figure S11 in Supporting Information). These results clearly evidence the 
inability of the amine bases alone (with basicities similar to that of the amino groups in UiO-66- $\mathrm{NH}_{2}$ ) to deprotonate the alcohol and carry out the esterification of LA. Next, we performed the reaction between $\mathrm{LA}$ and $\mathrm{EtOH}$ in the presence of both UiO-66 and an equivalent amount of the amine base. However, we did not observe any synergy between the Zr Lewis acid sites of UiO-66 and the soluble base: In the case of DMATA, the EL yield obtained was practically the same (or slightly lower) than with UiO-66 alone, while in the case of aniline, the EL yield was sensibly lower, practically identical to the blank experiment (see Figure S12 in Supporting Information). In our opinion, these results indicate that a partial neutralization of the acid sites of UiO-66 by the soluble amines is taking place to some extent, thus reducing the amount of acid centers available to catalyze the esterification reaction. Note that this neutralization cannot take place in $\mathrm{UiO}-66-\mathrm{NH}_{2}$, in which the basic amino groups are not mobile, but are fixed to the MOF walls as an integral part of the structure.

In a final experiment, LA and $\mathrm{EtOH}$ were reacted in the presence of equimolar mixtures of UiO-66 and solid materials containing amino groups: either 3-aminopropyl functionalized silica or Chitosan, both commercial samples purchased from Aldrich. Even if in this case the mutual neutralization of the acid and basic sites is not possible, we also noted that the catalytic activity of both solid mixtures felt down with respect to UiO-66 alone, probably due to a dilution effect (see Figure S12 in Supporting Information). These experiments clearly indicate that if a combined effect of the $\mathrm{Zr}$ and $\mathrm{NH}_{2}$ sites occurs, the amino groups should probably be close enough to the $\mathrm{Zr}$ acid sites to allow the simultaneous activation of both LA and $\mathrm{EtOH}$ to favor the reaction. This situation may occur in UiO-66- $\mathrm{NH}_{2}$, as shown in Scheme 3, but not in the solid mixtures of UiO-66 and 3-aminopropyl functionalized silica or Chitosan. The behaviour of UiO-66- $\mathrm{NH}_{2}$ as a bifucntional acid-base catalyst could also explain the higher TOF obtained $\left(230 \mathrm{~h}^{-1}\right)$ with respect to the (monofunctional) $p$-TSA (120 
$\mathrm{h}^{-1}$ ). As we will show later, the calculated TOF s for the esterification of LA with $n$-BuOH follow the same order: $\mathrm{UiO}-66-\mathrm{NH}_{2}>p-\mathrm{TSA} \approx \mathrm{UiO}-66$ (see Table 2).

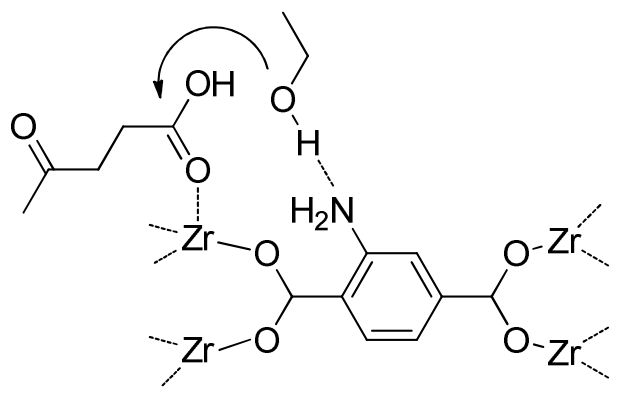

\section{Scheme 3}

According to the data shown in Figure 2c, there are other important differences between UiO-66 and UiO-66- $\mathrm{NH}_{2}$ that can be summarized as follows: i) the linear trend observed for UiO-66 passes through the origin, i.e., the catalytic activity of an ideal UiO-66 sample free of any linker defects would be expected to be negligible. However, this is not the case for UiO-66- $\mathrm{NH}_{2}$, for which a positive intercept is observed; ii) extrapolation of the data shown in Figure $2 \mathrm{c}$ seems to indicate that from a certain level of defects and above, the activity of UiO-66 would be expected to be the same, or even higher, than that of UiO-66- $\mathrm{NH}_{2}$. In other words, the synergy observed in UiO-66- $\mathrm{NH}_{2}$ samples with low content of defects seems to vanish when the amount of defects increases above a certain level; and iii) UiO-66- $\mathrm{NH}_{2}$ seems to be less sensitive to linker deficiency of the material, as deduced from the lower slope of the straight line in Figure 2c with respect to UiO-66. At present, we still don't have a satisfactory explanation for these results, which might indicate that other effects influence the catalytic activity of the UiO-66 type materials, such as electronic induction of the amino groups on the Lewis acid sites, or mutual interference due to a crowding of adsorbed products as the number of Lewis acid increases, thus hindering the dual activation in UiO-66- $\mathrm{NH}_{2}$. Moreover, this crowding effect is probably more relevant for UiO-66- $\mathrm{NH}_{2}$, for which the presence of the amino groups of the aminoterephthalate ligands already reduces the space available inside the structural cavities of the MOF (see below). 
Another parameter that in principle could be affecting the esterification rate over the different materials is the catalyst particle size. Large particle sizes could affect the mass transport properties, leading to a diffusion control of the reaction. Meanwhile, the amount of external active sites (in principle the most accessible to the substrates) would also decrease with the increase of the particle size. In order to investigate the possible influence of this parameter on the observed reaction rate, we have determined the average particle size (and the size dispersion) of each of the batches prepared for each material from the corresponding TEM images and the values were plotted versus the calculated rate constants. The results obtained are shown in Figure 2d. It is evident from this plot that the dependency of the activity on the particle size is different for UiO-66 and UiO-66- $\mathrm{NH}_{2}$. In the case of UiO-66, the esterification of LA is independent of the catalyst particle size, indicating that: i) there is no diffusion control of the reaction under the experimental conditions used; and ii) all the crystalline defects associated with linker deficiencies, located both at internal and external surfaces, may probably participate in the reaction. This is not surprising, in view of the relative dimensions of levulinic acid and the pore openings of UiO-66 (ca. $6 \AA$ A), which should allow the molecule to freely diffuse inside the pore system of the MOF and reach both internal and external active sites (see Figure S10 in Supporting Information). However, in the case of UiO-66- $\mathrm{NH}_{2}$, the presence of the amino groups further reduces the free pore openings, thus preventing or at least hindering diffusion of LA inside the pores, and reducing the space available inside the structural cavities of the MOF.

It is worth mentioning that thermal pre-treatment (activation) of the samples does not seem to have any influence on the observed catalytic activity of the samples. Thus, non pre-treated A1 and B1 samples showed practically the same activity than when the same samples were activated at $175^{\circ} \mathrm{C}$ under a vacuum for $3 \mathrm{~h}$ before adding the reaction substrates. Since thermal activation produces mainly desorption of physisorbed water from the pores and 
partial dehydroxylation of the $\left[\mathrm{Zr}_{6} \mathrm{O}_{4}(\mathrm{OH})_{4}\right]^{12+}$ clusters to $\left[\mathrm{Zr}_{6} \mathrm{O}_{6}\right]^{12+}$, it follows that this type of thermally generated defect sites (i.e., $\mu_{3}$-vacancies) do not decisively participate in the esterification reaction of LA.

\subsection{Production of n-butyl levulinate: Esterification of levulinic acid with n-butanol}

In view of the excellent results obtained for the esterification of levulinic acid with ethanol, we have extended the use of UiO-type Zr-MOFs to the production of another industrially relevant alkyl levulinate: $n$-butyl levulinate (BL). Besides its use as fuel additive, BL finds applications as plasticizing agent, solvent and fragrances (Bart et al., 1994).

Esterification of LA with $n$-butanol was performed at $120^{\circ} \mathrm{C}$ using $\mathrm{Zr}-\mathrm{MOF}$ as catalysts. The results obtained (Figure 3 and Table 2, entries 1 and 3) showed that BL formed almost quantitatively after $3 \mathrm{~h}$ over both $\mathrm{UiO}-66$ and $\mathrm{UiO}-66-\mathrm{NH}_{2}$, while only $46 \%$ yield was achieved in the corresponding blank experiment. As it was the case with the production of EL discussed in the previous section, the $\mathrm{Zr}-\mathrm{MOF}$ remained intact after the reaction and can be recovered and reused without significant loss of catalytic activity for at least 3 catalytic cycles (Table 2, entries 2 and 4). To put these catalytic results in context, note that the Zr-MOFs are much more active than protonic zeolites (Table 2, entries 5-8) (Maheria et al., 2013) and practically as active (though at higher catalyst loading) as Keggin-type heteropolyacids supported on acid-treated montmorillonite K10 under analogous reaction conditions (Table 2, entry 9) (Dharne and Bokade, 2011).

$<$ Insert Figure 4 near here $>$

$<$ Insert Table 2 near here $>$

\subsection{Production of long chain alkyl levulinates: Synthesis of Biomass-derived plasticizers} Esters of levulinic acid with long chain monohydric aliphatic alcohols having 
between 10 and 20 carbon atoms can be used as plasticizers in cellulose derivative compositions, such as lacquers for coating metal and wood, dopes for coating fabric, plastic compositions, coalescents in waterborne coating compositions and as plasticizers in blasting powders (Lawson and Salzberg, 1935). Such levulinate esters have reduced content of volatile organic compounds and exhibit improved coalescing activity as compared with esters of polyols, such as glycerol (Kuo and Hall, 2013). These long-chain alkyl levulinate esters are interesting compounds, due to the large availability of levulinic acid and the possibility to use also a biomass-derived alcohol, the so-called fatty alcohols, such as capric alcohol (1-decanol), lauryl alcohol (1-dodecanol, hereafter C12-OH), myristyl alcohol (1-tetradecanol), cetyl alcohol (1-hexadecanol, C16-OH), or arachidyl alcohol (1-eicosanol). Their synthesis can be carried out in the presence of a base, such as $\mathrm{NaOH}, \mathrm{KOH}$ or triethylamine; or with a mineral acid catalyst, such as sulfuric, hydrochloric or p-toluenesulfonic acid.

Based on the success of the $\mathrm{UiO}$ catalysts for the LA esterification with EtOH and $n$ - $\mathrm{BuOH}$, we extended the study to the preparation of long-chain alkyl levulinates, to evaluate the potential of the $\mathrm{Zr}$-contianing MOFs as the first example of recoverable and reusable solid acid catalysts reported so far. As substrates for this reaction, we have tested various saturated fatty alcohols $(\mathrm{C} 12-\mathrm{OH}$ and $\mathrm{C} 16-\mathrm{OH})$, as well as an unsaturated alcohol (oleyl alcohol, or cis-9-octadecen-1-ol, hereafter $\mathrm{C} 18: 1-\mathrm{OH})$, which has also a natural origin. A summary of the results obtained are shown in Table 3 and Figure 4.

$$
\begin{aligned}
& \text { < Insert Figure } 5 \text { near here> } \\
& <\text { Insert Table } 3 \text { near here> }
\end{aligned}
$$

Reaction of equimolar amounts of LA with $\mathrm{C} 12-\mathrm{OH}$ in the absence of catalyst produces $36 \mathrm{~mol} \%$ of the corresponding ester after $20 \mathrm{~h}$ of reaction at $80^{\circ} \mathrm{C}$, while this value increased to $90 \%$ when UiO-66 (sample batch B1) was used as catalyst under the same reaction 
conditions (Table 3, entries 1 and 2). Note that the amount of catalyst used was 9 mol\% $\mathrm{Zr}$ with respect to LA, which is sensibly higher than in the above reactions (only $1.8 \mathrm{~mol} \% \mathrm{Zr}$ was used in those cases). This amount of catalyst was selected to obtain good productivities, as moles of product converted per mol of $\mathrm{Zr}$ and per hour, in a reasonable reaction time (less than 1 day). Note that the large dimensions of the fatty alcohols prevents the diffusion of the reaction substrates to the active sites located at the internal surface of the MOF and therefore, only the $\mathrm{Zr}$ (defective) sites located at the external surface of the particles are most likely participating in the reaction.

Esterification of LA with longer fatty alcohols $(\mathrm{C} 16-\mathrm{OH}$ and $\mathrm{C} 18: 1-\mathrm{OH})$ results in a progressive drop of the catalytic activity with respect to $\mathrm{C} 12-\mathrm{OH}$. We have recently found (Cirujano et al., 2014) a similar trend in the esterification of fatty acids of increasing chain length and degree of unsaturation with $\mathrm{EtOH}$ and $\mathrm{MeOH}$, and attributed to a higher adsorption of the fatty acid (or fatty ester product) on the surface of the solid, which caused the progressive (reversible) deactivation of the catalyst. A similar effect could also explain the observed reactivity trend in the esterification of fatty alcohols with LA. Nevertheless, it is also worth mentioning that full conversion of LA and quantitative formation of the corresponding long chain alkyl levulinates can be attained by simply increasing the temperature of the reaction or the excess of alcohol used. Thus, when the reaction temperature was raised to $100^{\circ} \mathrm{C}$ and 1.5 equivalents of alcohol were used, $87 \%$ yield of the C18:1-LA ester was obtained after $20 \mathrm{~h}$. However, under these conditions, the yield obtained with the blank (autocatalyzed) reaction also increased (63\% yield after $20 \mathrm{~h}$ ), thus minimizing the role of the UiO-66 catalyzed reaction. In any case, the benefits of using UiO-66 as catalyst for the preparation of LA esters of long chain aliphatic alcohols are more evident for $\mathrm{C} 12-\mathrm{OH}$ than for the other alcohols. With respect to the autocatalyzed reaction, the presence of UiO-66 allows a lower operation temperature and, more importantly, the use of 
stoichiometric amounts of alcohols, while still ensuring a quantitative formation of the target ester. The use of a stoichiometric amount of alcohol is highly convenient from the environmental point of view and for the economy of the process, since it avoids the need for undesired separation and purification steps of the products. Thus, the use of UiO-66 as catalyst with 1 equivalent of alcohol and $80^{\circ} \mathrm{C}$ produces after $8 \mathrm{~h}$ the same yield of levulinate $(60 \%)$ than the blank experiment after $20 \mathrm{~h}$ at $100^{\circ} \mathrm{C}$ and with 1.5 equivalents of alcohol. Furthermore, the use of a solid acid catalyst for this reaction allows recovering the catalyst for reuse without significant loss of crystallinity or catalytic activity (see Table 3, entries 3, 6 and 9) and it should allow working in a fixed bed or in a continuous stirred-tank reactor. As we have commented above, this is the first report on the application of a solid acid catalyst to prepare this type of compounds.

\section{Conclusions}

Zr-containing MOFs, UiO-66 and UiO-66-NH2, have been found to be active, stable and reusable catalysts for the esterification of levulinic acid with various alcohols, viz., ethanol and $n$-buthanol, leading to biomass-derived alkyl levulinates of industrial relevance. As compared to other solid acid catalysts previously reported, the catalytic activity of the $\mathrm{Zr}$-MOFs is in general higher than most of the heterogeneous catalysts studied so far, including zeolites, with performances comparable with supported heteropolyacids and only clearly surpassed by highly acidic sulfated mixed $\mathrm{Zr}$ and $\mathrm{Ti}$ oxides. Interestingly, we have shown that the catalytic activity of the Zr-MOFs is critically dependent on the synthesis conditions and the resulting concentration of defects and particle size, with an almost 9-fold difference in catalytic activity. The same Zr-containing MOFs have also been successfully used for the esterification of LA with various biomass-derived long chain monohydric alcohols (fatty alcohols). This is the first report on the use of a solid acid catalysts for this reaction. 


\section{Acknowledgment}

Financial support from the Consolider-Ingenio 2010 (project MULTICAT), the SEVERO

OCHOA program, and the Spanish Ministry of Science and Innovation (project

MAT2011-29020-C02-01) is gratefully acknowledged.

\section{References}

Alaerts, L., Seguin, E., Poelman, H., Thibault-Starzyk, F., Jacobs, P.A., De Vos, D.E., 2006. Probing the Lewis acidity and catalytic activity of the metal-organic framework $\mathrm{Cu}_{3}(\mathrm{btc})_{2}$ (BTC = benzene-1,3,5-tricarboxylate). Chemistry-a European Journal 12, 7353-7363.

Bart, H.J., Reidetschlager, J., Dchatka, K., Lehmann, A., 1994. Kinetics of esterification of levulinic acid with n-butanol by homogeneous catalysts. Industrial \& Engineering Chemistry Research 33, 21-25.

Cavka, J.H., Jakobsen, S., Olsbye, U., Guillou, N., Lamberti, C., Bordiga, S., Lillerud, K.P., 2008. A New Zirconium Inorganic Building Brick Forming Metal Organic Frameworks with Exceptional Stability. Journal of the American Chemical Society 130, 13850-13851.

Cirujano, F.G., Corma, A., Llabrés i Xamena, F.X., 2014. Zirconium-containing Metal Organic Frameworks as solid acid catalysts for the esterification of free fatty acids: Synthesis of biosiesel and other compounds of interest. Catalysis Today, submited for publication.

Cirujano, F.G., Llabres i Xamena, F.X., Corma, A., 2012. MOFs as multifunctional catalysts: One-pot synthesis of menthol from citronellal over a bifunctional MIL-101 catalyst. Dalton Transactions 41, 4249-4254.

Corma, A., Garcia, H., Llabrés i Xamena, F.X., 2010a. Engineering Metal Organic Frameworks for catalysis Chemical Reviews 110, 4606-4655.

Corma, A., Iborra, S., Velty, A., 2007. Chemical routes for the transformation of biomass into chemicals. Chemical Reviews 107, 2411-2502.

Corma, A., Iglesias, M., Llabrés i Xamena, F.X., Sanchez, F., 2010b. $\mathrm{Cu}$ and $\mathrm{Au}$ Metal-Organic Frameworks Bridge the Gap between Homogeneous and Heterogeneous Catalysts for Alkene Cyclopropanation Reactions. Chemistry-a European Journal 16, 9789-9795.

Dharne, S., Bokade, V.V., 2011. Esterification of levulinic acid to n-butyl levulinate over heteropolyacid supported on acid-treated clay. Journal of Natural Gas Chemistry 20, 18-24.

Farrusseng, D., Aguado, S., Pinel, C., 2009. Metal-Organic Frameworks: Opportunities for Catalysis. Angewandte Chemie-International Edition 48, 7502-7513.

Fernandes, D.R., Rocha, A.S., Mai, E.F., Mota, C.J.A., Teixeira da Silva, V., 2012. Levulinic acid esterification with ethanol to ethyl levulinate production over solid acid catalysts. Applied Catalysis A. General 425-426, 199-204.

Fujita, M., Kwon, Y.J., Washizu, S., Ogura, K., 1994. Preparation, Clathration Ability, and Catalysis of a 2-Dimensional Square Network Material Composed of Cadmium(Ii) and 4,4'-Bipyridine. Journal of the American Chemical Society 116, 1151-1152.

Garcia-Garcia, P., Muller, M., Corma, A., 2014. MOF catalysis in relation to their homogeneous counterparts and conventional solid catalysts. Chemical Science 5, 2979-3007.

Gascon, J., Corma, A., Kapteijn, F., Llabrés i Xamena, F.X., 2014. Metal Organic Framework Catalysis: Quo vadis? ACS Catalysis 4, 361-378.

Hayes, D.J., 2009. An examination of biorefining processes, catalysts and challenges. 
Catalysis Today $145,138-151$.

Henschel, A., Gedrich, K., Kraehnert, R., Kaskel, S., 2008. Catalytic properties of MIL-101. Chemical Communications, 4192-4194.

Horike, S., Dinca, M., Tamaki, K., Long, J.R., 2008. Size-selective lewis acid catalysis in a microporous metal-organic framework with exposed $\mathrm{Mn}^{2+}$ coordination sites. Journal of the American Chemical Society 130, 5854-5855.

Kandiah, M., Nilsen, M.H., Usseglio, S., Jakobsen, S., Olsbye, U., Tilset, M., Larabi, C., Quadrelli, E.A., Bonino, F., Lillerud, K.P., 2010. Synthesis and Stability of Tagged UiO-66 Zr-MOFs. Chemistry of Materials 22, 6632-6640.

Kim, J., Kim, S.-N., Jang, H.-G., Seo, G., Ahn, W.-S., 2013. CO2 cycloaddition of styrene oxide over MOF catalysts. Applied Catalysis A. General 453, 175-180.

Kuo, T., Hall, P., 2013. Waterborne coating compositions containing low-VOC coalescents. US8383710.

Lawson, W.E., Salzberg, P.L., 1935. Levulinic acid ester. US2008720.

Lee, J.Y., Farha, O.K., Roberts, J., Scheidt, K.A., Nguyen, S.T., Hupp, J.T., 2009. Metal-organic framework materials as catalysts. Chemical Society Reviews 38, 1450-1459.

Li, Z., Wnetrzak, R., Kwapinski, W., Leahy, J.J., 2012. Synthesis and Characterization of Sulfated $\mathrm{TiO}_{2}$ Nanorods and $\mathrm{ZrO}_{2} / \mathrm{TiO}_{2}$ Nanocomposites for the Esterification of Biobased Organic Acid. ACS Applied Materials \& Interfaces 4, 4499-4505.

Llabrés i Xamena, F.X., Cirujano, F.G., Corma, A., 2012. An unexpected bifunctional acid base catalysis in IRMOF-3 for Knoevenagel condensation reactions. Microporous and Mesoporous Materials 157, 112-117.

Llabrés i Xamena, F.X., Gascon, J., 2013. Metal Organic Frameworks as Heterogeneous Catalysts, in: Spivey, J.J. (Ed.), RSC Catalysis Series, first ed. The Royal Society of Chemistry, Cambridge.

Maheria, K.C., Kozinski, J., Dalai, A., 2013. Esterification of Levulinic Acid to n-Butyl Levulinate Over Various Acidic Zeolites. Catalysis Letters 143, 1220-1225.

Nandiwale, K.Y., Niphadkar, P.S., Deshpande, S.S., Bokade, V.V., 2014. Esterification of renewable levulinic acid to ethyl levulinate biodiesel catalyzed by highly active and reusable desilicated H-ZSM-5. Journal of Chemical Technology and Biotechnology, doi. $10.1002 /$ jctb.4228.

Nandiwale, K.Y., Sonar, S.K., Niphadkar, P.S., Joshi, P.N., Deshpande, S.S., Patil, V.S., Bokade, V.V., 2013. Catalytic upgrading of renewable levulinic acid to ethyl levulinate biodiesel using dodecatungstophosphoric acid supported on desilicated H-ZSM-5 as catalyst. Applied Catalysis A. General 460-461, 90-98.

Pasquale, G., Vázquez, P., Romanelli, G., Baronetti, G., 2012. Catalytic upgrading of levulinic acid to ethyl levulinate using reusable silica-included Wells-Dawson heteropolyacid as catalyst. Catalysis Communications 18, 115-120.

Pérez-Mayoral, E., Cejka, J., 2011. $\left[\mathrm{Cu}_{3}(\mathrm{BTC})_{2}\right]$ : A Metal-Organic Framework Catalyst for the Friedlander Reaction. Chemcatchem 3, 157-159.

Schlichte, K., Kratzke, T., Kaskel, S., 2004. Improved synthesis, thermal stability and catalytic properties of the metal-organic framework compound $\mathrm{Cu}_{3}(\mathrm{BTC})_{2}$. Microporous and Mesoporous Materials 73, 81-88.

Valenzano, L., Civalleri, B., Chavan, S., Bordiga, S., Nilsen, M.H., Jakobsen, S., Lillerud, K.P., Lamberti, C., 2011. Disclosing the Complex Structure of UiO-66 Metal Organic Framework: A Synergic Combination of Experiment and Theory. Chemistry of Materials 23, 1700-1718.

Vermoortele, F., Ameloot, R., Vimont, A., Serre, C., De Vos, D., 2011. An amino-modified Zr-terephthalate metal-organic framework as an acid-base catalyst for cross-aldol condensation. Chemical Communications 47, 1521-1523. 
Vermoortele, F., Vandichel, M., Van de Voorde, B., Ameloot, R., Waroquier, M., Van Speybroeck, V., de Vos, D.E., 2012. Electronic Effects of Linker Substitution on Lewis Acid Catalysis with Metal-Organic Frameworks. Angewandte Chemie-International Edition 51, 4887-4890.

Wang, Z.Q., Cohen, S.M., 2009. Postsynthetic modification of metal-organic frameworks. Chemical Society Reviews 38, 1315-1329.

Wee, L.H., Lohe, M.R., Janssens, N., Kaskel, S., Martens, J.A., 2012. Fine tuning of the metal-organic framework $\mathrm{Cu}_{3}(\mathrm{BTC})_{2}$ HKUST-1 crystal size in the $100 \mathrm{~nm}$ to 5 micron range. Journal of Materials Chemistry 22, 13742-13746.

Yan, K., Wu, G., Wen, J., Chen, A., 2013. One-step synthesis of mesoporous $\mathrm{H}_{4} \mathrm{SiW}_{12} \mathrm{O}_{40}-\mathrm{SiO}_{2}$ catalysts for the production of methyl and ethyl levulinate biodiesel. Catalysis Communications 34, 58-63.

Zhang, J., Wu, S., Li, B., Zhang, H., 2012. Advances in the Catalytic Production of Valuable Levulinic Acid Derivatives. Chemcatchem 4, 1230-1237.

Zhang, X., Llabrés i Xamena, F.X., Corma, A., 2009. Gold(III) - Metal Organic Framework Bridges the Gap between Homogeneous and Heterogeneous Gold Catalysts. Journal of Catalysis 265, 155-160. 


\section{Tables}

Table 1. Summary of the catalytic results obtained for the esterification of levulinic acid (LA) with ethanol over Zr-MOFs and other heterogeneous catalysts reported in the literature. ${ }^{a}$

\begin{tabular}{|c|c|c|c|c|c|c|}
\hline Entry & Catalyst & EtOH:LA & $\begin{array}{c}\mathrm{T} \\
\left({ }^{\circ} \mathrm{C}\right)\end{array}$ & $\begin{array}{l}\text { EL Yield } \\
(\mathrm{mol} \%)^{b}\end{array}$ & $\begin{array}{c}\operatorname{TOF}^{c} / \\
\text { Product. }^{d} \\
\left(\mathbf{h}^{-1}\right)\end{array}$ & Reference \\
\hline 1 & Blank & $15: 1$ & 78 & $3 / 5.4(4 \mathrm{~h} / 8 \mathrm{~h})$ & - & This work \\
\hline 2 & $p$-TSA & $15: 1$ & 78 & $96 / 99(4 \mathrm{~h} / 8 \mathrm{~h})$ & $120 / 7$ & “ \\
\hline 3 & $\mathrm{UiO}-66-\mathrm{NH}_{2}$ & $15: 1$ & 78 & $78 / 95$ (4h/8h) & $29(230)^{e} / 7$ & “ \\
\hline 4 & UiO-66- $\mathrm{NH}_{2}\left(3^{\text {rd }}\right.$ use $)$ & $15: 1$ & 78 & 69/92 (4h/8h) & $15(119)^{e} / 6$ & “ \\
\hline 5 & UiO-66 & $15: 1$ & 78 & 78/94 (4h/8h) & $31(117)^{e} / 7$ & “ \\
\hline 6 & UiO-66 ( $3^{\text {rd }}$ use $)$ & $15: 1$ & 78 & $74 / 93(4 h / 8 h)$ & $16(61)^{e} / 6$ & “ \\
\hline 7 & UiO-66 & $5: 1$ & 78 & $49(4 h)$ & n.d./7 & “ \\
\hline 8 & UiO-66 & $5: 1$ & 100 & $73(4 h)$ & n.d./10 & “ \\
\hline 9 & Amberlyst-15 & $5: 1$ & 70 & $55(5 \mathrm{~h})$ & - & (Fernandes et al., 2012) \\
\hline 10 & Sulfated $\mathrm{TiO}_{2}$ & $5: 1$ & 70 & $40(5 \mathrm{~h})$ & - & “ \\
\hline 11 & Sulfated $\mathrm{ZrO}_{2}$ & $5: 1$ & 70 & $10(5 h)$ & - & “ \\
\hline 12 & H-MCM-22 & $5: 1$ & 70 & $12(5 \mathrm{~h})$ & - & “ \\
\hline 13 & H-MOR & $5: 1$ & 70 & $4(5 h)$ & - & “ \\
\hline 14 & $\mathrm{SO}_{4}\left[\left(\mathrm{ZrO}_{2}\right)_{1.1}\left(\mathrm{TiO}_{2}\right)_{8.4}\right]$ & $2.5: 1$ & 105 & $90.4(3.5 \mathrm{~h})$ & - & (Li et al., 2012) \\
\hline 15 & $\mathrm{SO}_{4}\left(\mathrm{TiO}_{2}\right)_{20}$ nanorods & $2.5: 1$ & 105 & $83.2(4 \mathrm{~h})$ & - & “ \\
\hline 16 & DTPA/DHZSM-5 & $6: 1$ & 78 & $82(4 h)$ & $-/ 205$ & (Nandiwale et al., 2013) \\
\hline 17 & H-ZSM-5 & $6: 1$ & 90 & $20(5 h)$ & $-/ 0.3$ & (Nandiwale et al., 2014) \\
\hline 18 & DH-ZSM-5 & $6: 1$ & 90 & $38(5 \mathrm{~h})$ & $-/ 0.5$ & “ \\
\hline 19 & DH-ZSM-5 & $10: 1$ & 90 & $75(5 h)$ & $-/ 1$ & “ \\
\hline 20 & $\mathrm{H}_{4} \mathrm{SiW}_{12} \mathrm{O}_{40} / \mathrm{SiO}_{2}$ & $18: 1$ & 75 & $67(6 h)$ & $-/ 11$ & (Yan et al., 2013) \\
\hline 21 & 40WD-S & $64: 1$ & 78 & $76(10 \mathrm{~h})$ & $64 / 15$ & (Pasquale et al., 2012) \\
\hline \multicolumn{7}{|c|}{$\begin{array}{l}{ }^{a} \text { Catalyst loading: } 1.8 \mathrm{mo} \% \mathrm{Zr} \text { with respect to LA. Other reaction conditions (EtOH:LA } \\
\text { molar ratio and temperature) are indicated in the table. Data for UiO-66 and UiO-66-NH } 2 \\
\text { correspond to batches B } 1 \text { and } \mathrm{A} 1 \text {, respectively (see text for details). }{ }^{b} \text { Determined by GC. EL } \\
\text { was the only product detected. }{ }^{c} \text { Turnover frequencies }(T O F) \text { cannot be calculated for most of } \\
\text { the reactions taken from literature since no conversions at short reaction times were provided. } \\
{ }^{d} \text { Productivity of the catalyst, as moles of product formed per mol of catalyst and per hour, } \\
\text { calculated at the end of the reaction, when enough data is provided in the original paper. } \\
\text { Recalculated TOFs considering that only } \mathrm{Zr} \text { ions associated to linker defects catalyze the } \\
\text { esterification reaction (see text for details). }\end{array}$} \\
\hline
\end{tabular}


Table 2. Summary of the catalytic results obtained for the esterification of levulinic acid (LA) with $n$-butanol over Zr-MOFs and other heterogeneous catalysts reported in the literature. ${ }^{a}$

\begin{tabular}{|c|c|c|c|c|c|}
\hline Entry & Catalyst & BuOH:LA & $\begin{array}{l}\text { BL Yield } \\
(\mathrm{mol} \%)^{b}\end{array}$ & $\begin{array}{c}\text { TOF/ } \\
\text { Product. }^{c}\left(\mathbf{h}^{-1}\right)\end{array}$ & Reference \\
\hline 1 & $p-\mathrm{TSA}^{d}$ & $6: 1$ & $89 / 99(0.5 \mathrm{~h} / 2 \mathrm{~h})$ & $399 / 212$ & This work \\
\hline 2 & $\mathrm{UiO}-66-\mathrm{NH}_{2}$ & $6: 1$ & $91 / 99(2 \mathrm{~h} / 5 \mathrm{~h})$ & $72(571)^{e} / 11$ & “ \\
\hline 3 & $\mathrm{UiO}-66-\mathrm{NH}_{2}\left(3^{\text {rd }}\right.$ use $)$ & $6: 1$ & $88 / 99(4 h / 6 h)$ & $53(421)^{e} / 9$ & “ \\
\hline 4 & UiO-66 & $6: 1$ & $95 / 99(2 \mathrm{~h} / 5 \mathrm{~h})$ & $106(401)^{e} / 11$ & “ \\
\hline 5 & $\mathrm{UiO}-66\left(3^{\text {rd }}\right.$ use $)$ & $6: 1$ & 96/99 (4h/6h) & $59(223)^{e} / 9$ & “ \\
\hline 6 & H-BEA & $7: 1$ & $82(4 h)$ & $7.1 / 15$ & (Maheria et al., 2013) \\
\hline 7 & H-MOR & $7: 1$ & $30(4 \mathrm{~h})$ & $-/ 4.1$ & “ \\
\hline 8 & $\mathrm{H}-\mathrm{Y}$ & $7: 1$ & $32(4 h)$ & $-/ 1.4$ & “ \\
\hline 9 & H-ZSM-5 & $7: 1$ & $31(4 \mathrm{~h})$ & $-/ 6.4$ & “ \\
\hline 10 & $\mathrm{HPA} / \mathrm{K} 10$ & $6: 1$ & $97(4 h)$ & $-/ 205$ & $\begin{array}{c}\text { (Dharne and Bokade, } \\
\text { 2011) }\end{array}$ \\
\hline
\end{tabular}

${ }^{a}$ Catalyst loading: $1.8 \mathrm{mo} \% \mathrm{Zr}$ with respect to LA; BuOH:LA molar ratio as indicated, $120^{\circ} \mathrm{C}$ in all cases. Data for UiO-66 and UiO-66- $\mathrm{NH}_{2}$ correspond to batches $\mathrm{B} 1$ and A1, respectively (see text for details). ${ }^{b}$ Determined by GC. BL was the only product detected. ${ }^{c}$ Productivity of the catalyst, as moles of product formed per mol of catalyst and per hour, calculated at the end of the reaction. ${ }^{d} 0.8 \mathrm{~mol} \% \mathrm{H}^{+}$with respect to LA was used. ${ }^{e}$ Recalculated TOFs considering that only $\mathrm{Zr}$ ions associated to linker defects catalyze the esterification reaction (see text for details). 
Table 3. Summary of the catalytic results obtained for the esterification of levulinic acid (LA) with various fatty alcohols over $\mathrm{UiO}-66 .^{a}$

\begin{tabular}{clccc}
\hline Entry & Catalyst & Alcohol & $\begin{array}{c}\text { Ester Yield } \\
(\mathbf{m o l} \%)^{\boldsymbol{b}}\end{array}$ & TOF $^{c}\left(\mathbf{h}^{-\mathbf{1}}\right)$ \\
\hline 1 & Blank & C12-OH & $21 / 36(8 \mathrm{~h} / 20 \mathrm{~h})$ & - \\
2 & UiO-66 & & $72 / 90(8 \mathrm{~h} / 20 \mathrm{~h})$ & $4(15)^{d}$ \\
3 & UiO-66 $\left(3^{\text {rd }}\right.$ use $)$ & $81(20 \mathrm{~h})$ & n.d. \\
4 & H-ZSM-5 (Si/Al=15) & & $93(20 \mathrm{~h})$ & \\
5 & H-USY $(\mathrm{Si} / \mathrm{Al}=15)$ & & $53(20 \mathrm{~h})$ & \\
4 & Blank & C16-OH & $29 / 51(8 \mathrm{~h} / 20 \mathrm{~h})$ & - \\
5 & UiO-66 & & $66 / 82(8 \mathrm{~h} / 20 \mathrm{~h})$ & $3.6(14)^{d}$ \\
6 & UiO-66 $\left(3^{\text {rd }}\right.$ use $)$ & & $78(8 \mathrm{~h} / 20 \mathrm{~h})$ & n.d. \\
7 & Blank & $\mathrm{C} 18: 1-\mathrm{OH}$ & $21 / 26(8 \mathrm{~h} / 20 \mathrm{~h})$ & - \\
8 & UiO-66 & & $60 / 62(8 \mathrm{~h} / 20 \mathrm{~h})$ & $3.8(14)^{d}$ \\
9 & UiO-66 $\left(3^{\text {rd }}\right.$ use $)$ & & $59(20 \mathrm{~h})$ & n.d. \\
\hline
\end{tabular}

${ }^{a}$ Catalyst loading: 9 mo\% $\mathrm{Zr}$ with respect to LA. Alcohol:LA molar ratio and temperature used were $1: 1$ and $80^{\circ} \mathrm{C}$. Data for UiO-66 correspond to batch B1 (see text for details). ${ }^{b}$ Determined by GC. Levulinate ester was the only product detected in all cases. ${ }^{c}$ Turnover frequencies $(T O F)$, as moles of product formed per mol of catalyst and per hour, calculated at the initial reaction times. ${ }^{d}$ Recalculated TOFs considering that only $\mathrm{Zr}$ ions associated to linker defects catalyze the esterification reaction (see text for details). 


\section{Figure Captions}

Figure 1. (Left) Structure of the UiO-66 materials, showing the face centred close cubic packing of $\mathrm{Zr}_{6}$ octahedral clusters connected by twelve terephthalate linkers. (Right) $\mathrm{Zr}^{4+}$ coordination vacancies created when a linker molecule is missing are evidenced by red arrows. $\mathrm{Zr}^{4+}$, Pink; C, Light blue; O, Red. $\mathrm{H}$ atoms are omitted for clarity.

Figure 2. a) Yields of ethyl levulinate (EL) obtained over UiO-66 (- - - , UiO-66- $\mathrm{NH}_{2}$ $(-\mathrm{O}-)$, and in a blank experiment without catalyst $(-\Delta-)$.

Figure 3. Yield of ethyl levulinate (EL) obtained over a) UiO-66, batches B1 to B4 (from top to bottom); and $b$ ) UiO-66- $\mathrm{NH}_{2}$, batches $\mathrm{A} 1$ to $\mathrm{A} 4$ (from top to bottom). For each curve, the calculated pseudo-first order kinetic rate constant is indicated (see Supporting Information for details). $c$ ) Dependency of the esterification pseudo-first order rate constant $(k)$ on the linker deficiency of the catalyst. Same symbols as in part a) for UiO-66 and $\mathrm{UiO}-66-\mathrm{NH}_{2} ;\left(^{*}\right)$ corresponds to a UiO-66- $\mathrm{NO}_{2}$ sample. $d$ ) Dependency of the esterification rate constant on the particle size of the catalyst. Error bars represent the size dispersion (95\% confidence interval) for each catalyst. Same symbols as in part $c$ ) for UiO-66 and UiO-66- $\mathrm{NH}_{2}$.

Figure 4. Yields of $n$-buthyl levulinate (BL) obtained over UiO-66 (-匹-) and UiO-66- $\mathrm{NH}_{2}$ $(-\mathrm{O}-)$.

Figure 5. Esterification of levulinic acid with various biomass-derived fatty alcohols without catalyst $(-\Delta-)$ or in the presence of UiO-66 (- -). a) C12-OH: Lauryl alcohol (1-dodecanol); b) C16-OH: Cetyl alcohol (1-hexadecanol); c) C18:1-OH: Oleyl alcohol (cis-9-octadecen-1-ol). 
Figures
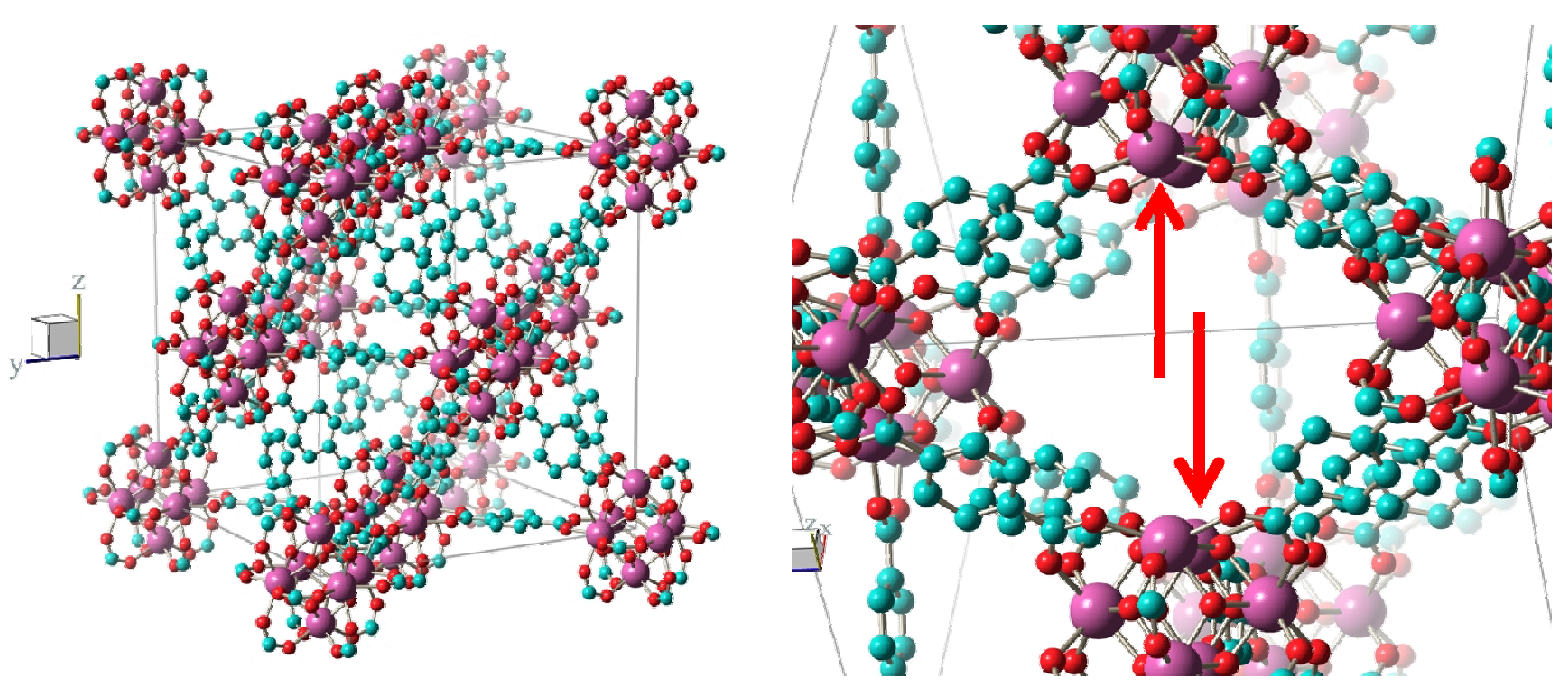

Figure 1. 


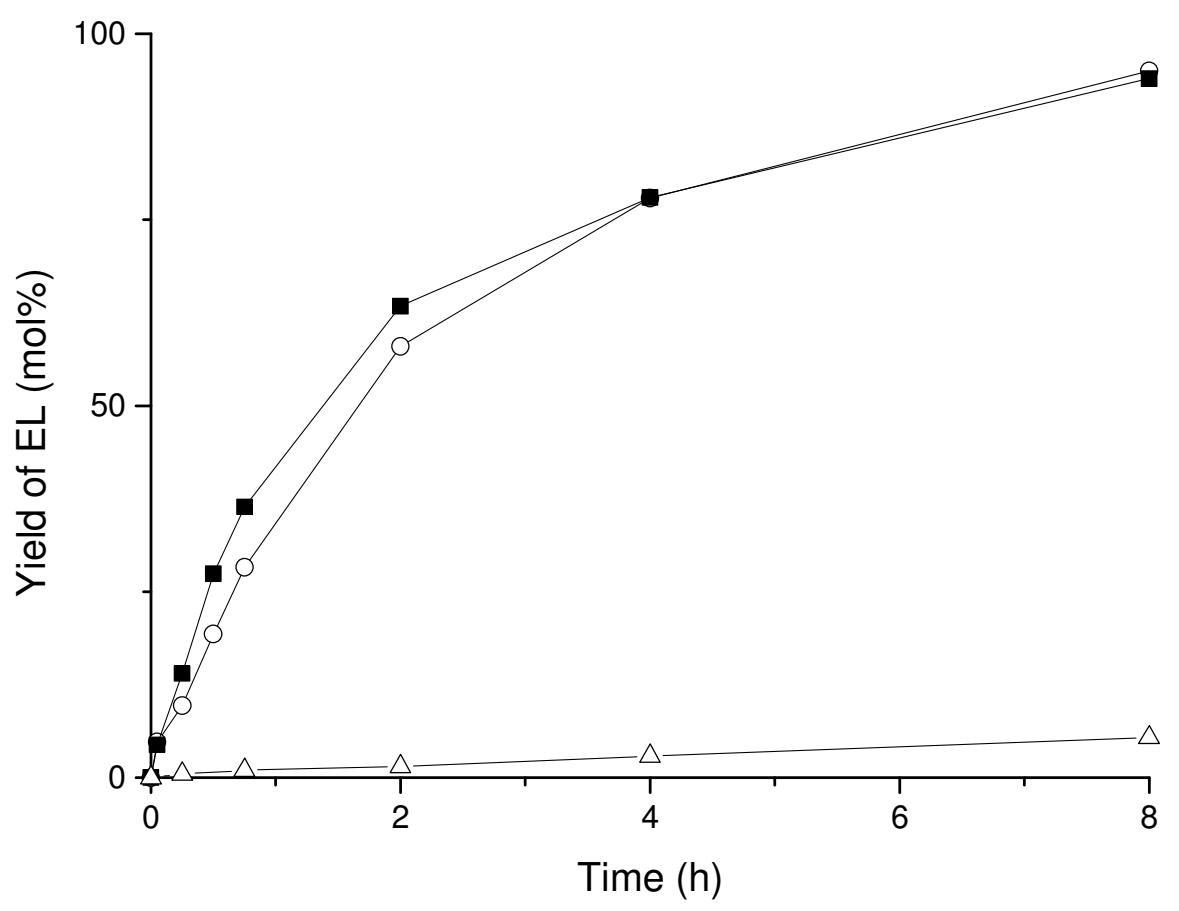

Figure 2. 

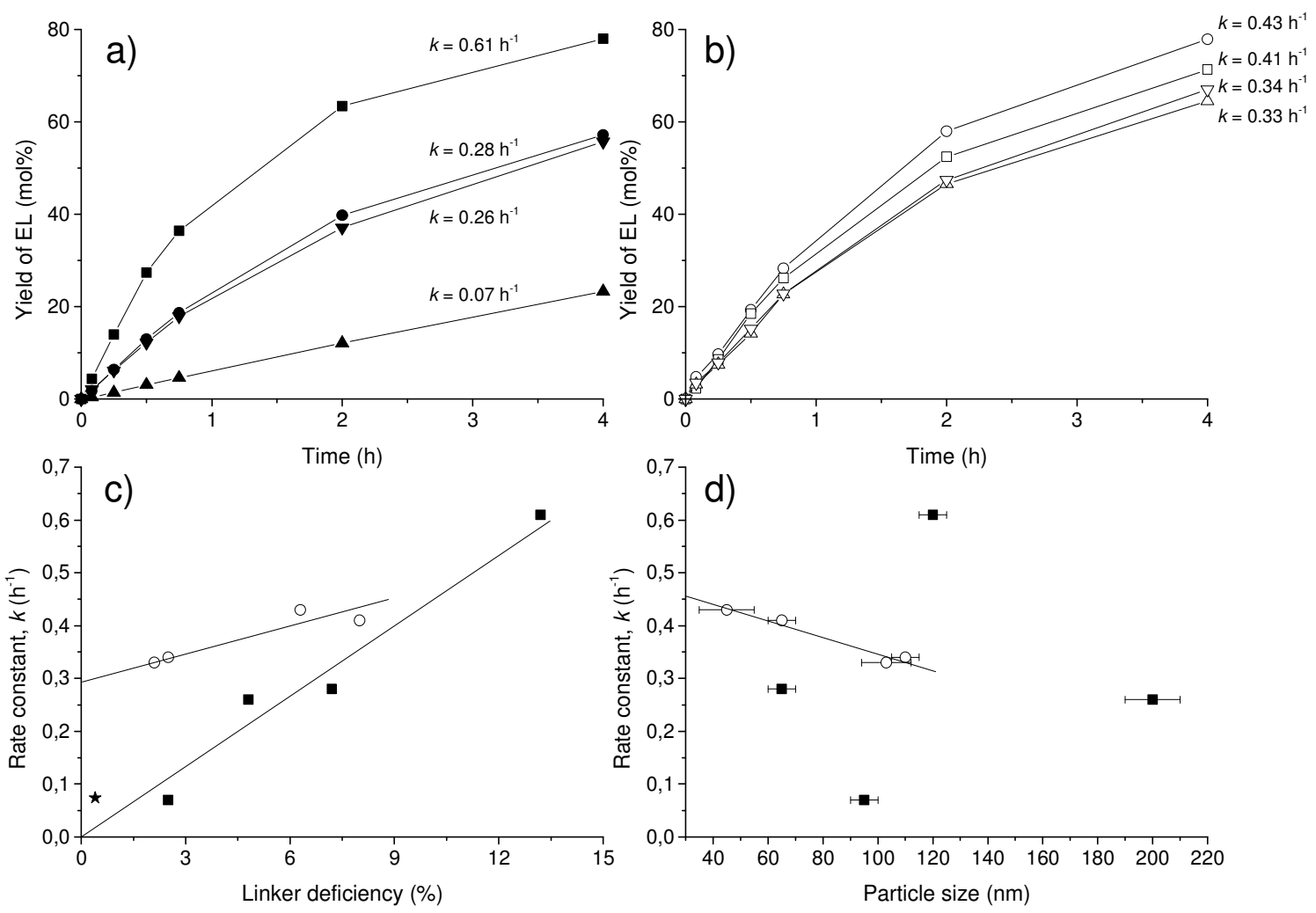

Figure 3. 


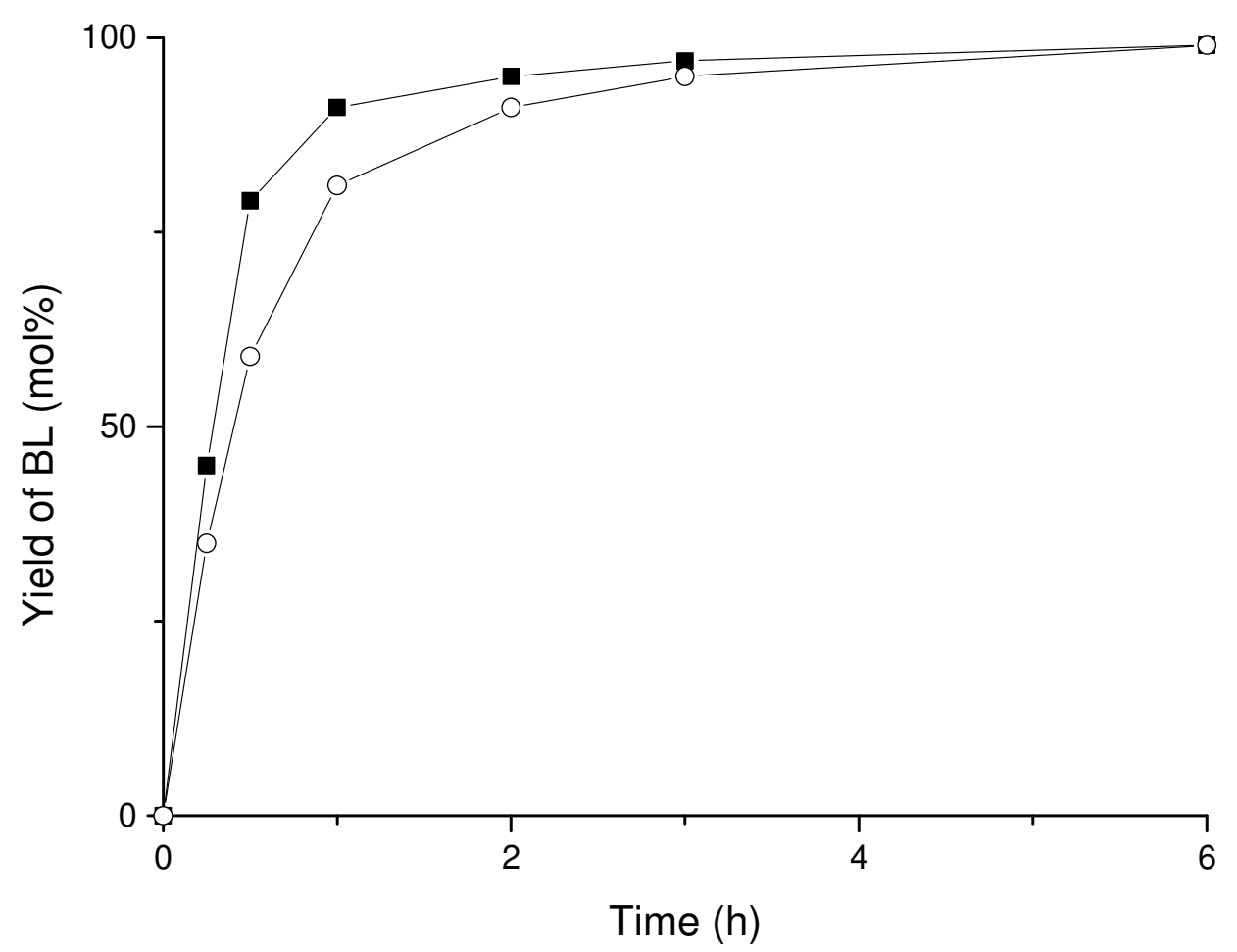

Figure 4. 


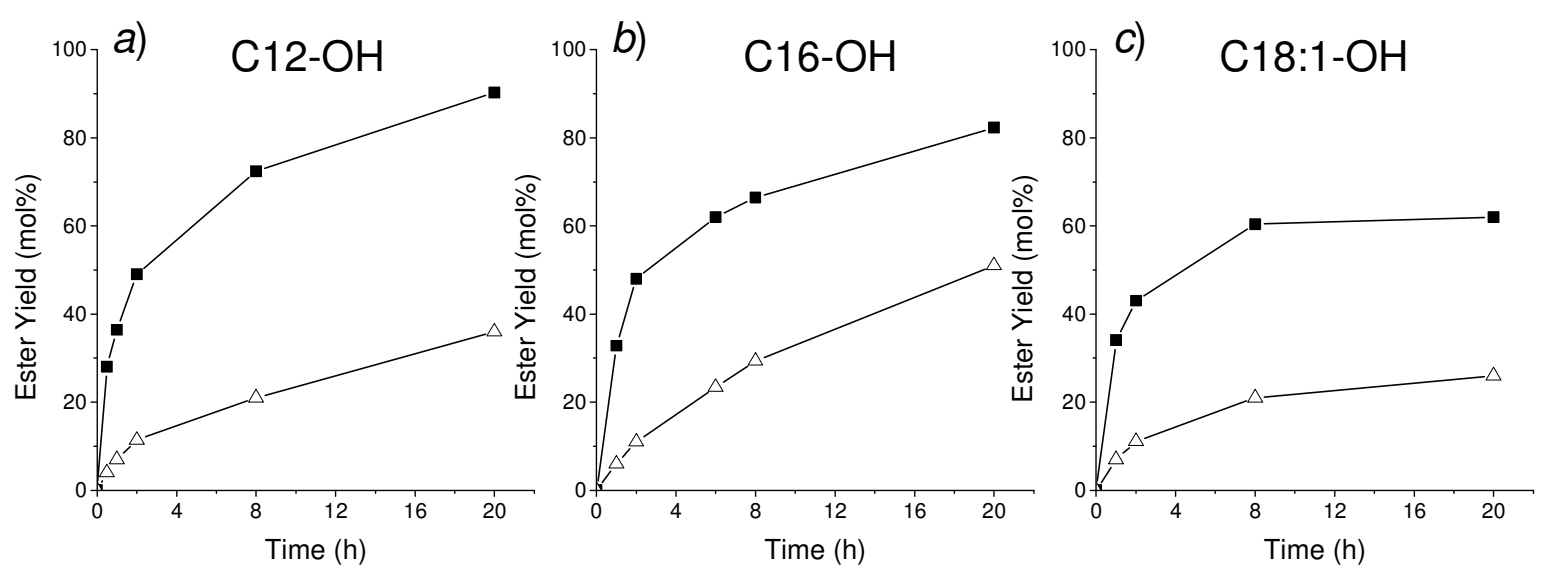

Figure 5. 